\title{
La Huelga de los 100 días. Conflictividad laboral en los frigoríficos argentinos a comienzos de la década de $1960^{*}$
}

\section{The 100-Day Strike. Labor Unrest in Argentine Meat Processing Plants in the Early 1960s}

\author{
Verónica Vogelmann ** \\ (D) https://orcid.org/0000-0003-1582-788X \\ Investigaciones Socio-históricas Regionales (ISHIR)-Consejo Nacional de Investigaciones \\ Científicas y Técnicas (CONICET)-Universidad Nacional de Rosario (UNR) \\ vogelmann@ishir-conicet.gov.ar
}

Resumen: El artículo tiene como objetivo analizar la conflictividad laboral desarrollada en los frigoríficos argentinos a comienzos de la década de los sesen-

* Esta investigación se realizó en el marco de los proyectos "Condiciones laborales y experiencias de luchas y organización gremiales de los y las trabajadores(as) agroindustriales. Contribuciones desde el análisis antropológico y socio histórico en Rosario y su región”, financiado por el Consejo Nacional de Investigaciones Científicas y Técnicas (CONICET, 2019-2021); e "Historia y Antropología Social de los Trabajadores en Argentina" (dirigida por la doctora Silvia Simonassi), financiado por la Universidad Nacional de Rosario.

** Doctora en Humanidades y Artes, mención Antropología. Miembro investigador en la Unidad Ejecutora de ConicET, Instituto de Investigaciones Socio-históricas Regionales (ISHIR) Rosario, Argentina. Investigadora adjunta del Consejo Nacional de Investigaciones Científicas y Técnicas (CONicet). Docente de la Universidad Nacional de Rosario. Unidad Académica: Facultad de Humanidades y Artes.

cómo citaR: Vogelmann, V. (2021). La Huelga de los 100 días. Conflictividad laboral en los frigoríficos argentinos a comienzos de la década de 1960. Secuencia (110), e1775. DoI: https://doi.org/10.18234/secuencia. v0i110.1775 
ta. Se aborda el proceso de lucha de alcance nacional iniciado con la llamada "Huelga de los 100 días", focalizando el abordaje en las características que el conflicto adquirió en la región sur del Gran Rosario, provincia de Santa Fe. Son retomadas fuentes de diverso origen (prensa sindical, partidaria, documentación estatal, archivos privados y prensa nacional y local). Se concluye afirmando que, a pesar de la derrota sufrida por los trabajadores y el deterioro en las condiciones laborales impuesto, surgió un nuevo activismo gremial con una significativa presencia en el interior de los espacios laborales. El estudio realizado contribuye a la construcción de conocimiento de los procesos de lucha, las transformaciones en los procesos de trabajo y las formas de organización gremial de los trabajadores.

Palabras clave: conflictividad laboral; industria frigorífica; proceso de trabajo; organización gremial; Argentina.

Abstract: The aim of this article is to analyze the labor conflict developed in the Argentine meat-packing industry, in the early sixties. The national struggle process -known as "The hundred-day strike" is fully described. The focus of this study the was on the characteristics that de conflict acquired in the Gran Rosario region, of Santa Fe province. The analysis resort to wide variety of sources (union and party newspapers, official government documents, private archives, and local and national press). It concludes that even though workers suffered heavy defeat in labor conditions and rights, a new trade union activism in the working. This research contributes to the struggles, workings processes transformations and the trade union organization literature.

Keywords: labor conflict; meat-packing industry; workings processes; trade union organization; Argentina.

Recibido: 2 de agosto de 2019 Aceptado: 17 de enero de 2020

Publicado: 23 de abril de 2021 


\section{INTRODUCCIÓN}

$E^{1}$ objetivo de este trabajo es abordar la conflictividad obrera en los frigoríficos argentinos durante los primeros años de la década de los sesenta, centrando el análisis en una importante huelga de alcance nacional que tuvo un impacto decisivo en los procesos productivos y en la dinámica sindical de los trabajadores de la carne de todo el país, la llamada "huelga de los 100 días" (Historia de la Federación de la Carne, 1997, p. 39).

Desde un enfoque regional se busca generar conocimiento sobre las particularidades que alcanzó dicho conflicto en la ciudad de Rosario y en la vecina Villa Gobernador Gálvez, provincia de Santa Fe, una de las principales zonas de desarrollo de la industria frigorífica en Argentina.

En efecto, la región sur de Rosario se fue consolidando como un polo de desarrollo de la industria frigorífica, desde la instalación de la empresa Swift en 1924. Durante las décadas de los años cincuenta y sesenta la región fue receptora de otras firmas vinculadas con el procesamiento cárnico ${ }^{1}$ consolidando al sector frigorífico como uno de los más dinámicos en materia de empleo. ${ }^{2}$ Un dato a subrayar es que el Swift de Rosario es el único de los grandes frigoríficos de capitales extranjeros, instalados en el país hacia fines del siglo xIX y comienzos del xx, que aún sobrevive en Argentina.

De manera que el énfasis estará puesto en una mirada regional considerada como una construcción históricamente determinada y delimitada, más que por las características geográficas o político-administrativas, por las tramas sociales, políticas y económicas construidas por los actores. En otras palabras, se trata de una categoría socialmente espacializada (Fernández, 2007) que, en nuestro caso, remiten tanto al proceso de instalación y desarrollo de la industria frigorífica en la región y en el país, como a las características particulares que adquirió la organización obrera y las formas de expresión de la conflictividad laboral.

${ }^{1}$ Se instalaron los frigoríficos: Subproductos Ganaderos Rosario S. A. (Sugarosa) en 1956; Paladini, Villa Diego, Litoral Argentino S. A. y Lequio a principios de la década de los sesenta. También los frigoríficos La Tropa, La Jamonera y la Corporación Argentina de Productores de Carne (CAP) en 1962 (Vogelmann, 2012).

${ }^{2}$ A comienzos de la década de los sesenta, Swift de Rosario poseía un plantel que oscilaba los 5000 trabajadores, mientras que los frigoríficos pequeños y medianos sumaban alrededor de 3000 empleados. A nivel nacional, considerando exclusivamente al sector de capitales concentrados, la industria de la carne empleaba alrededor de 30000 trabajadores. Estimaciones construidas triangulando información proveniente de la prensa local, nacional y gremial. 
En tal sentido, el abordaje busca indagar en las relaciones que se establecen entre la escala regional y nacional, no sólo porque el mismo objeto de estudio así lo demanda sino también porque se parte de una perspectiva teórico-metodológica que procura indagar en las potencialidades de los procesos particulares en vinculación con la dinámica más amplia, recuperando dicha particularidad para complejizar la totalidad (Fernández, 2007).

Asimismo, partimos de una concepción de la conflictividad laboral como expresión del antagonismo propio de las relaciones de producción. De manera que el énfasis analítico está puesto no sólo en las expresiones "abiertas" de la conflictividad, aquellas que se desarrollaron a través de medidas de fuerza que cobraron notoriedad y estado público, sino que interesa abordar también aspectos de la cotidianidad laboral que remiten a las formas de organización del trabajo al interior de las plantas y a experiencias gremiales que tendieron a resistir la avanzada patronal en las condiciones de trabajo. Vinculada con esta orientación es posible destacar que la originalidad del aporte se inscribe en la articulación de diversas dimensiones de análisis (el proceso de lucha, el impacto de la derrota, los cambios en la organización del trabajo y la aparición de un nuevo activismo).

Desde esta perspectiva se retoman diversas fuentes provenientes del ámbito gremial (documentación e información laboral, publicaciones sindicales, boletines y volantes de organizaciones gremiales); de archivos privados (memorias de militantes sindicales); del Ministerio de Trabajo y Seguridad Social de la Nación (мтуss), (convenios colectivos de trabajo, actas y expedientes); de la prensa partidaria y periódica local y nacional. El abordaje de este material posibilita el análisis de procesos político-económicos, empresariales y gremiales que confluyeron en el escenario del conflicto objeto del presente estudio.

El artículo está organizado en distintos apartados, en el primero se analiza con profundidad la gran huelga nacional de los 100 días del año 1962, se identifican algunos antecedentes significativos y se aborda la dinámica de la organización sindical, las medidas de fuerza y las respuestas patronales. En el segundo apartado se describe el proceso de declive de la huelga y el impacto de la derrota en los colectivos obreros. En tercer lugar, se identifican los cambios en la organización del trabajo sistematizando las principales transformaciones impuestas en la cotidianidad laboral. Por último, se avanza en el análisis de experiencias que, desde distintos ámbitos de actuación y a través de un nuevo activismo, se plantearon la tarea de reorganizar a los trabajadores 
de los frigoríficos, en este punto se destaca la importancia que estas nuevas experiencias gremiales han tenido en la configuración de agrupamientos que tuvieron protagonismo en décadas posteriores, particularmente en Rosario. Finalmente, se presentan un conjunto de conclusiones.

El estudio realizado dialoga con una vasta bibliografía que aborda la conflictividad y las relaciones laborales durante los años sesenta en América Latina y Argentina relevando los procesos de lucha y organización del movimiento obrero tras el triunfo de la revolución cubana (Simonassi, 2016a). En Argentina los enfoques y discusiones en el campo historiográfico sobre el periodo refieren a los procesos de radicalización de las luchas obreras hacia finales de la década del sesenta y principios de los setenta (Balvé y Balvé, 2005; Brennan, 1996; Cerutti y Resels, 2006; Löbbe, 2009; Pasquali, 2010; Viano, 2000).

Las investigaciones sobre el tema otorgan importancia analítica a "la forma específica de organización sindical politizada de los trabajadores al nivel de la producción", la denominada "anomalía argentina" (Gilly, 1986, p. 20) que ha otorgado un carácter original a la estructura sindical argentina respecto a otros países de América Latina (Basualdo, 2010). Esta originalidad se inscribe en el peso que históricamente han tenido las formas de representación gremial al interior de los lugares de trabajo a través de delegados, comisiones internas, y cuerpos de delegado. En tal sentido, diversos estudios buscan reponer "los vasos que comunicaban las grandes luchas con las disputas cotidianas" (Ghigliani, 2015, p. 2) a través del análisis de los procesos de trabajo y de las formas de representación directa.

Asimismo, la bibliografía especializada subraya una serie de rasgos que caracterizan al modelo sindical argentino y que se fueron consolidando desde la década de 1940, en primer lugar, el desarrollo de una estructura sindical nacional por rama de actividad, tendente a unificar al movimiento obrero y a desalentar el establecimiento de diferencias entre categorías de trabajadores dentro de una actividad similar sobre la base de la ocupación o la ubicación geográfica. Este rasgo ha sido señalado como un elemento de distinción frente a otros modelos de organización sindical latinoamericanos como el chileno o el brasileño que en sus códigos y normativas "procuran deliberadamente fragmentar al movimiento obrero" (Doyon, 2006, p. 151). En segundo lugar, la afirmación de un sistema de negociaciones colectivas que establecía la autoridad del Estado en tanto agente encargado de definir los sindicatos habilitados para intervenir en las negociaciones colectivas en virtud de la representativi- 
$\operatorname{dad}^{3} \mathrm{y}$ de homologar los convenios colectivos de trabajo negociados entre las organizaciones sindicales y patronales.

Desde estas coordenadas los estudios sobre el movimiento obrero a finales de la década de los cincuenta y los primeros años de los sesenta debaten en torno a las características que asumió la conflictividad laboral. Las investigaciones subrayan la importancia que asumieron los cambios en el modelo de acumulación capitalista y los intentos por aumentar la productividad laboral, imponiendo mayores ritmos de producción y limitando el alcance de la organización sindical en los lugares de trabajo. Algunos autores abordan los procesos de racionalización y la conflictividad en los sectores frigorífico y metalúrgicos a partir del análisis de laudos arbitrales (Ferraro y Schiavi, 2012), o convenios colectivos de trabajo y demandas patronales (James, 1981). Existen trabajos que analizan la dinámica de la industria frigorífica y sus trabajadores en regiones importantes del país como Berisso (Lobato, 2001), y en otras localidades de menores dimensiones como General Cerri (Baier, 2012), ambas ubicadas en la provincia de Buenos Aires.

Un debate que atraviesa la literatura sobre el periodo se inscribe en las consecuencias de las derrotas en los procesos de lucha de finales de la década de los cincuenta en el movimiento obrero. Al respecto, algunos análisis caracterizan a los primeros años de la década de los sesenta en término de desmoralización y desmovilización (James, 2006), mientras que otros enfatizan la continuación de los conflictos en un contexto regresivo. Para estos últimos, los resultados de los procesos de lucha no implicaron, en todos los casos, perdidas de conquistas, por el contrario, en términos generales se mantuvieron niveles importantes de redistribución del ingreso y de ocupación laboral (Schneider, 2005).

Desde una mirada regional, se han realizado aportes a una literatura centrada en los sucesos desarrollados en la ciudad de Buenos Aires y sus alrededores. En otras regiones, los estudios sobre la protesta obrera durante los primeros años sesenta son ineludibles para comprender los procesos de radicalización de finales de esa década en Córdoba y la "constitución de la cultura de resistencia y confrontación" que caracterizó al periodo (Gordillo, 1999, p.

${ }_{3}^{3}$ La legislación en Argentina reconoce la posibilidad de constituir sindicatos libremente, sin embargo, "establece, al mismo tiempo, un sistema de mayor representatividad que distingue dos tipos de sindicatos: por un lado, los sindicatos con personería gremial, que reciben tal reconocimiento por parte del Estado en virtud de poseer la mayor cantidad de afiliados cotizantes; por el otro, los sindicatos simplemente inscriptos" (Campos y Campos, 2017, p. 11). 
269). En Rosario las investigaciones problematizan acerca de la conformación de una tradición obrera y sindical distintiva caracterizada por la acción unitaria de distintas corrientes político-sindicales y la masividad y radicalidad que adquirieron las luchas durante esos años (Simonassi y Vogelmann, 2017; 2018).

$\mathrm{Al}$ centrar la atención en la industria frigorífica y la historia de lucha y organización de sus trabajadores durante estos años uno de los aspectos a subrayar tiene que ver con la profunda reestructuración por la que estaba atravesando la rama a nivel mundial y su impacto en distintos países de América del Sur. En efecto, la denominada "industria grande", compuesta por empresas frigoríficas de capital extranjero instaladas en países como Argentina, Uruguay y Brasil hacia fines del siglo xIX y comienzos del Xx, ingresó en un proceso de declive y paulatina retirada. Al mismo tiempo fueron surgiendo y expandiendo su influencia establecimientos frigoríficos de nuevo tipo, de capitales nacionales y con estructuras de menores dimensiones (Azcuy Ameghino, 2007; Buxedas, 1983; Gayoso y Repetto, 2013). De manera que, las luchas de los obreros de la carne hacia finales de los años cincuenta y durante la década de los sesenta estuvieron signadas por un escenario de racionalización, cierres de plantas y numerosos despidos (Baier, 2012; Lobato, 2001; Porrini, 2004; Salas, 2006). En consecuencia, parte de la literatura se focaliza en las transformaciones urbanas, el patrimonio industrial; las representaciones, memorias e identidades construidas por los habitantes de las ciudades y barrios obreros tras los cierres de estas significativas fuentes de trabajo (Bretal, 2016; De Oliveira, 2015; Michelon, 2012; Porrini, 2018). Como mencionamos, de este escenario general se diferenció la región de Rosario tanto por la supervivencia a lo largo de la historia de su principal frigorífico como por el impulso que adquirió el sector con la instalación de establecimientos de menores dimensiones (Vogelmann, 2015). De manera que este proceso consolidó en la región un sector que durante el periodo bajo estudio mostraba claros signos de su pérdida de relevancia económica a nivel nacional a favor de la expansión de sectores dinámicos como automotriz, petróleo, mecánica y química (Schvarzer, 1996).

En definitiva, es posible afirmar que el conflicto que analizamos surgió en un contexto signado por una industria frigorífica que comenzaba a mostrar un fuerte deterioro, y que a su vez empalmaban con procesos político-económicos generales tendentes a transformar el modelo de acumulación en distintos países de América del Sur. Argentina en particular, desde mediados de la década de los cincuenta, estuvo atravesada por golpes de Estado 
sucesivos que buscaron desmantelar la herencia del gobierno peronista (19461955), frenar la creciente movilización social y transformar la matriz económica del país avanzando sobre las conquistas obreras. Durante estos años, el triunfo electoral de Arturo Frondizi (1958-1962) supuso la profundización de un proceso de industrialización en áreas estratégicas a través del otorgamiento de concesiones al capital extranjero. Tras su derrocamiento militar, en marzo de 1962, José María Guido (1962-1963) ocupó la presidencia. Con un nuevo llamado a elecciones presidenciales asumió el radical Arturo Illia (1963-1966) hasta que otro golpe de Estado impuso al general Onganía como presidente, en junio de 1966.

Uno de los rasgos sobresalientes por estos años fue la respuesta represiva del Estado ante las protestas obreras. La puesta en práctica del Plan de Conmoción Interna (CONINTES) durante el gobierno democrático de Frondizi fue una de sus expresiones paradigmáticas. Dicho Plan se basaba en una legislación coercitiva que otorgaba al poder ejecutivo "poderes de guerra" (Fayó, 2007, p. 8) al habilitar la represión militar en el interior de las fronteras nacionales en casos de alteración grave del orden público (Simonassi, 2016b). De este modo, la intervención del ejército se produjo en conflictos políticos y gremiales de relevancia como el protagonizado, entre otros gremios, por los trabajadores del frigorífico Lisandro de la Torre en resistencia al proceso privatizador en el año 1959 (Salas, 2006).

En definitiva, el periodo analizado se caracterizó por una dinámica de inestabilidad política, por la proscripción y persecución al peronismo y al comunismo y, centralmente, por una extendida ofensiva contra los trabajadores y sus organizaciones. Estas tendencias configuraron el escenario general de luchas obreras que tuvieron un significativo impacto en las construcciones gremiales de los años posteriores.

\section{SALARIO, MEDIDAS DE FUERZA Y CIERRES DE PLANTAS. ANTECEDENTES E INICIOS DEL CONFLICTO}

La "Huelga de los 100 días", iniciada en los frigoríficos argentinos en el mes de agosto de 1962, se originó por la exigencia de los representantes empresarios de la denominada "industria grande" de otorgar aumentos salariales atados a modificaciones en la organización del trabajo que avanzaban sobre las condiciones establecidas por el Convenio Colectivo vigente, firmado en el año 
1946 (en adelante сст/46). Esta avanzada patronal no configuraba un hecho aislado sino que, como mencionamos, los intentos por imponer nuevos sistemas de trabajo, cláusulas de productividad y de limitar la actuación de los cuerpos de delegados y comisiones internas determinaron la dinámica de los conflictos y negociaciones en gremios como textiles y metalúrgicos (James, 1981). Además de los conflictos por la imposición de cambios en las formas de organización del trabajo, durante ese año las medidas de fuerza decretadas por distintos gremios giraron en torno a reclamos por atrasos y falta de pago de los haberes y por la pérdida de puestos de trabajo (Schneider, 2005).

A comienzos de 1962 la Federación Gremial del Personal de la Industria Frigorífica y Afines (en adelante la Federación) realizó diversas gestiones tendentes a obtener aumento de salarios para los trabajadores del sector. Es importante señalar que la Federación fue un actor significativo en todo el proceso, se trata del órgano de representación sindical de segundo grado que nucleaba a los sindicatos de los trabajadores de los frigoríficos con actuación en regiones y/o establecimientos de distintos puntos del país. Constituía el órgano de representación nacional y era el actor autorizado para entablar las negociaciones colectivas con las patronales. Formaba parte de la Confederación General del Trabajo (CGT) y, para el momento que estamos analizando, agrupaba a unas 70 filiales, tanto de la industria chica como grande, y a 50000 trabajadores. ${ }^{4}$

De manera que, mientras la Federación exigía una recomposición salarial de $40 \%$, las patronales se mantenían inflexibles, negándose a entablar negociaciones aduciendo la existencia de conflictos en distintos establecimientos. ${ }^{5}$ La negativa empresarial a concurrir a las instancias de negociación paritaria fue acelerando el conflicto que presentaba antecedentes recientes.

${ }^{4}$ Informes laborales del Servicio de Documentación e Información Laboral (DIL). Febrero de 1962. Núm. 24. Biblioteca del Centro de Estudios e Investigaciones Laborales del Consejo Nacional de Investigaciones Científicas y Técnicas (en adelante BCEIL/ConiCET), Buenos Aires.

${ }^{5}$ Durante esos meses la Federación amenazó con la adopción de medidas de fuerza y recurrió al MTyss como instancia de mediación y vía de acercamiento al sector empresarial. La Capital de Rosario y La Prensa de Buenos Aires, abril a julio de 1962. Fondo Hemerográfico. Biblioteca Argentina Dr. Juan Álvarez (en adelante FH-HBA), Rosario. 


\section{Antecedentes de la gran Huelga}

Desde comienzos de la década de los sesenta los trabajadores del sector protagonizaron distintas medidas de fuerza para enfrentar suspensiones y despidos generalizados, para el año 1961 las cesantías ascendían a 10000 trabajadores. ${ }^{6}$ En ese mismo año comenzó un conflicto paradigmático, que pronto adquirió relieve político nacional, en el frigorífico Wilson de Avellaneda, provincia de Buenos Aires, cuando la empresa luego de realizar numerosos despidos amenazó con abandonar el país. ${ }^{7}$ Otro dato para destacar es que, durante las negociaciones paritarias de 1961, las patronales concentradas del sector recurrieron al cierre de establecimientos en respuesta a las medidas de fuerza decretadas por la Federación. ${ }^{8}$

Asimismo, las tensiones y divisiones al interior de la Federación influyeron de manera significativa en la dinámica del conflicto. Las disputas entabladas se expresaron a través de dirigentes sindicales con proyecciones nacionales que, aunque compartían su adscripción peronista y el sostenimiento de prácticas sindicales dialoguistas y negociadoras, confrontaron durante estos años por la conducción de la Federación. Los actores protagonistas de estas disputas fueron, por un lado, el secretario general en funciones de la Federación Eleuterio Cardoso, figura destacada en la escena sindical nacional por haber expresado de forma pública la necesidad de que el movimiento obrero eligiera un camino evolucionista y flexible, capaz de reemplazar a "la lucha de clases" "por la lucha por objetivos concretos dentro del orden legal" rompiendo con "prejuicios" para "entrar a conversar con representantes de las fuerzas armadas, de la Iglesia y los sectores económicos".

Por otro lado, se encontraba el referente de la lista Blanca Ernesto Escalada que, por esos años, se fue consolidando como referente sindical en

${ }^{6}$ Se registraron despidos en los frigoríficos Gualeguaychú, Anglo, Wilson, Smithfield, entre otros, y se denunciaron persecuciones a los representantes sindicales al interior de los establecimientos. Informes laborales DIL. Mayo y julio de 1961. Núm. 15 y 17. BCEIL/CONICET, Buenos Aires.

${ }^{7}$ Informes laborales DIL. Mayo, julio y septiembre de 1961. Núm. 15-17-19. BCEIL/CONICET, Buenos Aires.

${ }^{8}$ Informes laborales DiL. Junio de 1961. Núm. 16. BCeIL/Conicet, Buenos Aires.

${ }^{9}$ Periódico Nuestra Palabra del Partido Comunista, Buenos Aires, 16 de agosto de 1960. Archivo Gastón Gesrik, Partido Comunista. Provincia de Santa Fe (en adelante AGG-PC), Rosario. El discurso de Cardoso fue pronunciado en el Congreso de la Federación de la Carne en agosto de 1960. 
establecimientos de la denominada "industria nacional" como el frigorífico Gualeguaychú, la Corporación Argentina de Productores de Carne (CAP) y el Argentino. Referentes de esa lista realizaron ocupaciones del edificio de la Federación y medidas de fuerza tendentes a acrecentar las disputas por la dirección de la organización sindical nacional. En muchas de estas acciones tuvieron intervención autoridad del Estado del poder ejecutivo y judicial. ${ }^{10}$

En el ámbito regional, el panorama del Sindicato de la Carne de Rosario era diferente. En febrero de 1961 ganó las elecciones el Movimiento Unitario Lista Marrón liderado por el Partido Comunista (PC) e integrado por trabajadores radicales, peronistas e independientes. ${ }^{11}$ Esta victoria fue parte de un proceso de actuación prolongada del PC al interior del gremio, que remite al momento en que el Swift se instaló en la región en la década de los veinte (Vogelmann y Menotti, 2010). Desde el golpe de Estado de 1955 esta presencia se expresó a través de una política unitaria a nivel de las plantas y de oposición a los lineamientos dialoguistas y conciliadores de las conducciones peronistas tanto de la Federación como del Sindicato rosarino. ${ }^{12}$ A pesar de estos antecedentes, el triunfo de esta lista en el Sindicato de Rosario fue un hecho resonante a nivel nacional por tratarse de una agrupación liderada por el PC en un gremio de fuerte tradición peronista.

Desde el inicio, la nueva Comisión Directiva enfrentó la abierta hostilidad del Swift que se negó a reconocer oficialmente a la conducción sindical. Para justificar su accionar la empresa aducía que el secretario general del Sindicato, Ramón Zarza, había sido despedido. En efecto, el despido se

${ }^{10}$ Periódico El Trabajador de la Carne de la Federación del Personal de la Industria de la Carne, Derivados y Afines. Diciembre de 1958. Centro de Documentación de las Organizaciones Político-Militares Argentinas-El Topo Blindado (en adelante CD-тв). Recuperado de http://eltopoblindado.com

${ }^{11}$ En los comicios de ese año el peronismo fue divido en dos listas. Sobre un total de 3780 votos la Lista Marrón dirigida por Ramón Zarza obtuvo 1 620; la Lista Violeta dirigida por Jacito Serbali 1200 ; y la Lista Verde encabezada por el hasta ese entonces secretario general, Constantino Zorilla, obtuvo 960 votos. Memorias escritas por militante del Partido Comunista y dirigente del Sindicato de Mataderos de Rosario, Memorias Óscar González. "Historia del Movimiento Unitario ‘Lista Marrón' del gremio de la carne, Rosario, 1 de junio de 1988. Fondo particular. 3 folios. AGG-PC, Rosario.

${ }^{12}$ La Lista Marrón ocupó secretarías a nivel local y nacional. En 1956 en el Sindicato rosarino accedió a una representación en la Comisión Directiva por la minoría (con 577 votos) y en 1959 (con 1200 votos) obtuvo un congresal al Consejo Federal. Memorias Óscar González, “Historia del Movimiento Unitario 'Lista Marrón' del gremio de la carne”, Rosario, 1 de junio de 1988. Fondo particular. 3 folios. AGG-PC, Rosario. 
basó en ausencia injustificada, luego de que fuera detenido en el marco del Plan CONINTES acusado de participar de actos protagonizados por comandos de la resistencia peronista en Rosario. ${ }^{13}$ El desconocimiento de la dirección sindical por parte del Swift conllevaba dificultades de distinto orden, por un lado, financieras ya que la empresa no liquidaba al Sindicato las retenciones realizadas, $y$, por el otro, gremiales al impedir que miembros de la dirección sindical ocuparan sus puestos de representación en la Paritaria local, órgano gremial que funcionaba al interior de las plantas industriales. De manera irregular, los representantes empresariales seleccionaron, de acuerdo a su conveniencia, a los trabajadores que constituirían dicho organismo, desplazando a la Comisión Directiva del ámbito de negociación interno donde se dirimían, centralmente, conflictos vinculados con las formas de organización del trabajo (Menotti, 2008; Shapiro, 2015).

En ese escenario, la Lista Marrón buscó rodearse de solidaridad articulando vinculaciones con distintas organizaciones de la sociedad civil como vecinales y agrupaciones de mujeres, siendo uno de sus principales reclamos el reconocimiento del Concejo Directivo por parte de Swift. En tal sentido, se realizaron gestiones legales y pedidos formales ante el Ministerio del Trabajo. Sindicatos de otras regiones, como el de Avellaneda, y la Federación se solidarizaban y se expresaban públicamente a favor del reclamo.

Asimismo, dirigió conflictos a nivel de planta como el que tuvo lugar en la sección de cámaras frías del frigorífico Swift en respuesta a la decisión empresarial de sumar tareas a los puestos de trabajo. El sindicato decretó un paro de una hora de duración en la sección y la respuesta patronal fueron las suspensiones. Ante la arbitrariedad de la decisión patronal el sindicato radicó denuncias en el Ministerio de Trabajo y envió una delegación a la Federación. ${ }^{14}$

Otras de las dificultades que debió sortear la conducción del sindicato local estuvo dada por la paulatina consolidación de sectores gremiales vinculados con la peronista lista Violeta de Jacinto Serbali, que buscaron deslegitimar las gestiones y articular fuerza con el fin de desplazar a la conducción liderada por el comunismo. En respuesta, las autoridades sindicales convoca-

${ }^{13}$ Memorias Óscar González, "Hist. Mov. Sind. Trabajadores de la Carne". Sin fecha. Fondo particular. 8 folios. AGG-PC, Rosario.

${ }^{14}$ Periódico Nuestra Palabra del Partido Comunista, Buenos Aires, 16 de mayo de 1961. AGG-PC, Rosario. 
ban a asambleas para reafirmar su liderazgo. ${ }^{15}$ A pesar de las dificultades, la lista unitaria Marrón fue confirmada en la conducción del sindicato rosarino en las elecciones a congresales de la Federación de agosto de 1961, donde fueron elegidos los cinco congresales que presentan.

En síntesis, es posible afirmar que en los albores de la gran huelga de 1962 los trabajadores de los frigoríficos venían resistiendo arremetidas significativas por parte de las patronales concentradas del sector y se encontraban enfrentando profundas divisiones que debilitaban la organización gremial tanto a nivel nacional como en la región. En Rosario, este proceso se vio reforzado por la embestida del frigorífico Swift contra el sindicato, al negarse a reconocer a su comisión directiva liderada por el PC.

\section{Se inicia el conflicto}

Llegado el mes julio de 1962 y ante el vencimiento del Convenio Colectivo, la Federación amenazaba con "la proximidad de la adopción de medidas de fuerza" en respuesta a la intransigencia patronal que obstaculizaba la renovación del convenio y el otorgamiento de aumentos salariales. ${ }^{16}$ En ese marco, el 9 de agosto dispuso paros sorpresivos y quite de colaboración en todos los frigoríficos de la "industria grande" del país, con diferentes horarios de iniciación que comenzaban con una hora por turno e iban en ascenso. ${ }^{17}$

La respuesta de las grandes firmas del sector fue inmediata, al día siguiente, dispusieron el cierre de los establecimientos y la suspensión de todo el personal hasta tanto la Federación tomara el compromiso formal de "normalizar el trabajo" y se dispusiera "a discutir bases aceptables para incrementar los jornales y eliminar" lo que llamaban "trabas y abusos que afectan al normal y eficiente desarrollo de las operaciones industriales y la productividad". ${ }^{18}$

${ }^{15}$ Periódico Nuestra Palabra del Partido Comunista, Buenos Aires, 19 de septiembre de 1961. AGG-PC, Rosario.

${ }^{16}$ La Prensa, Buenos Aires, 1 de julio 1962. FH-HBA, Rosario; Informes laborales DIL. Mayo y junio de 1962. Núms. 27-28. BCeIL/Conicet, Buenos Aires.

${ }_{17}^{17}$ La Prensa, Buenos Aires, 9 y 10 de agosto 1962; La Capital, Rosario, 12 de agosto de 1962. FH-HBA. Rosario; Informes laborales DIL. Agosto de 1962. Núm. 29. BCEIL/Conicet, Buenos Aires.

${ }^{18}$ Las empresas firmantes eran CAP, Swift, Armour, Anglo, Bovril, La Blanca, y Liebig. La Prensa, Buenos Aires, y La Capital, Rosario, 11 de agosto de 1962. FH-HBA, Rosario. 
El lock out se extendió por más de un mes e implicó la suspensión de 30000 trabajadores. Para sostener la medida las empresas contaron con las fuerzas represivas del Estado que permanecieron ocupando y custodiando las plantas, y reprimiendo los intentos de ocupación obrera que se fueron registrando en distintos puntos del país. En Rosario, aunque no se desarrollaron disturbios en las inmediaciones de Swift, luego de establecido el lock out se reforzó la vigilancia policial y se dispuso modificar los puntos terminales de las líneas de transporte público impidiendo que llegaran hasta las puertas del frigorífico. Días después "se dispuso la ocupación del establecimiento por efectivo de gendarmería nacional a mando de Agustín Feced" ${ }^{19}$ quien asumió la custodia "mientras no se disponga el levantamiento de cierre dispuesto por la empresa". ${ }^{20}$

Ante el cierre de los establecimientos productivos, la Federación intentó llevar adelante las negociaciones a través de la Comisión de Salarios. Organizó mesas redondas donde se procuraba analizar el estado crítico de la industria frigorífica argumentando que el proceso de declive y los altos costos productivos del sector no derivaban del salario obrero sino que obedecían a "deficiencias notorias en materia de tecnificación". ${ }^{21}$ En todo momento la estrategia seguida tendía a establecer ámbitos de negociación, pero se enfrentaba con un sector patronal que sistemáticamente se negaba a participar de cualquier instancia de diálogo. Del mismo modo buscó articular el apoyo y la solidaridad de la CGT, las 62 Organizaciones ${ }^{22}$ y de funcionarios del poder ejecutivo nacional. ${ }^{23}$

En Rosario el escenario del conflicto tuvo algunas particularidades que contrastaron con la dinámica nacional. Aunque el Sindicato de Rosario procuró estrechar vínculos y generar canales de diálogo con distintos actores de la región como presidentes comunales, fuerzas armadas y vecinales, la estrategia principal estuvo dada en activar movilizaciones y mantener la unidad de los trabajadores.

${ }^{19}$ Agustín Feced, comandante mayor de gendarmería nacional. Entre 1976 y 1978, durante la última dictadura militar, fue interventor de la policía rosarina desde donde comandó uno de los circuitos del terrorismo de Estado en la región.

${ }^{20}$ La Capital, Rosario, 16 y 18 de agosto de 1962; Crónica, Rosario, 18 de agosto de 1962; La Prensa, Buenos Aires, 14 de agosto de 1962. FH-HBA, Rosario.

${ }^{21}$ Informes laborales DIL. Agosto de 1962. Núm. 30, p. 18. BCEIL/ConiCET, Buenos Aires.

${ }^{22}$ Agrupamiento del peronismo gremial surgido en 1957.

${ }^{23}$ A cargo de José María Guido quien asumió la presidencia en el marco del golpe militar de marzo de 1962. 
El gremio se declaró en estado de asamblea permanente y buscó rodearse de solidaridad participando de $\operatorname{actos}^{24} \mathrm{y}$ organizando mesas redondas ${ }^{25}$ y movilizaciones. ${ }^{26}$ Ante la presencia policial y de gendarmería en la zona sur de Rosario y en Villa Gobernador Gálvez, una modalidad de visibilización que adoptó el sindicato fue organizar movilizaciones que se dirigían al centro de la ciudad de Rosario, algunas se concentraban en plazas y otras tenían como destino las instalaciones donde funcionaba el diario de mayor influencia en la región. En todos los casos las fuerzas represivas actuaron para disuadir a los manifestantes. Asimismo, las asambleas de trabajadores y vecinos fueron masivas, en ellas además de difundir información sobre la marcha del conflicto se buscaba dar la palabra a los obreros de distintas secciones y áreas de la fábrica y se convocaba a dirigentes sindicales de la ciudad para que manifestaran su apoyo y solidaridad. ${ }^{27}$

En el local sindical se instaló "un comedor" donde se proporcionaba "alimentación a obreros y familiares". Para su funcionamiento se organizaban comisiones de trabajo que recibían mercadería donada por comerciantes de la zona solidarios con los trabajadores en lucha. Otras comisiones procuraban recaudar subsidios para los huelguistas y garantizar las tareas de propaganda. ${ }^{28}$

En definitiva, el sindicato local acató las medidas de fuerza decretadas por la Federación, pero en el marco del lock out buscó dar dinamismo al conflicto promoviendo asambleas, movilizaciones y actividades de difusión tendentes a promover la solidaridad. Estrategias similares se desarrollaron en otras localidades del país, como Berisso, donde se encontraban emplazados importantes frigoríficos de gran capital como Swift y Armour que contaban con fuertes estructuras sindicales (Lobato, 2001). Mientras que en pequeñas

${ }^{24}$ Zarza fue uno de los oradores del acto organizado por la CGT-Rosario en agosto de 1962. En su discurso denunció el accionar de los grandes frigoríficos y llamó a conformar comandos de lucha. La Capital, Rosario, 1 de septiembre 1962. FH-HBA, Rosario.

${ }^{25}$ Periódico Nuestra Palabra del Partido Comunista, Buenos Aires, 18 de septiembre de 1962. AGG-PC, Rosario; Participaron la CGT-Local, distintos sindicatos, agrupaciones estudiantiles, sociales, vecinales y partidos políticos.

${ }^{26}$ La Capital, Rosario, 18 de agosto de 1962. FH-HBA, Rosario.

${ }^{27}$ Periódico Nuestra Palabra del Partido Comunista, Buenos Aires, 15 de agosto de 1962. AGG-PC, Rosario.

${ }^{28}$ La Capital y Crónica, Rosario, 29 de agosto 1962. FH-HBA, Rosario; Volante gremial "Los trabajadores comunistas contestan a Jacinto Serbali”, Rosario, 25 de marzo de 1964, 4 folios. CD-тв. Recuperado de http://eltopoblindado.com 
localidades como en General Cerri, de la provincia de Buenos Aires, la dinámica de la conflictividad estuvo orientada a instrumentar las resoluciones definidas por la Federación (Baier, 2012). Sin duda, las heterogéneas experiencias estaban atravesadas por la importancia de la industria frigorífica en la zona, la cantidad de obreros afectados y por la forma en que se expresaban las tensiones gremiales internas.

Más allá de estos matices, la dureza de la ofensiva patronal impactaba fuertemente en las filas obreras en las distintas regiones. Como rememoraba un protagonista de estas jornadas, a medida que transcurrían las semanas comenzaba a "sentirse el hambre y la desesperación" ${ }^{29}$ En ese escenario, promediando el lock out las empresas formularon su oferta a través de comunicados de prensa donde ofrecían un incremento salarial de $22 \%$ condicionado a aumentos en la productividad derivados de un "ordenamiento de los trabajos". En sus declaraciones volvían a hacer pública las intenciones de transformar los procesos laborales, atando los aumentos de salarios a la productividad, cuestión que no estaban dispuestos a negociar. ${ }^{30}$

\section{APERTURA DE PLANTAS, REPRESIÓN Y ARREMETIDA PATRONAL. LA HUELGA LLEGA A SU FIN}

El día 20 de septiembre de 1962 las empresas frigoríficas resolvieron "reanudar sus operaciones". Habían transcurrido 44 días de lock out y la resolución se tomó sin mediar ningún tipo de diálogo con la Federación. En los comunicados de prensa las patronales detallaban a los obreros las condiciones innegociables que regirían al interior de los lugares de trabajo. Expresaban que los aumentos salariales serían del orden de $35 \%$, unos puntos más que los ofrecidos en primera instancia, y se encontraban atados inexorablemente al despliegue de profundas reestructuraciones en las condiciones de trabajo. Las mismas aparecían apuntadas en carteles colgados "en la entrada de las fábricas" y se iban comunicando de manera individual a cada trabajador que era convocado a reincorporarse a su puesto de trabajo. Los representantes de las

${ }^{29}$ Memorias escritas del militante comunista y obrero de Swift Santiago Simón, "Memorias de Santiago Simón, un trabajador del Frigorífico Swift", s/ref., p. 19. Agradezco a Paulo Menotti el haberme facilitado el material.

30 "Comunicado de prensa", La Tribuna, Rosario, 4 de septiembre de 1962; "Comunicado de prensa”, La Capital, Rosario, 6 de septiembre de 1962. FH-HBA, Rosario. 
empresas advertían también que las reincorporaciones se producirían a medida que "los servicios de cada trabajador" fueran "necesarios". ${ }^{31}$

Esta medida patronal fue acompañada por un decreto del poder ejecutivo que anulaba las elecciones de la Comisión Directiva de la Federación realizadas en $1961 .^{32}$ Con este decreto se profundizaban las tensiones al interior de la organización gremial nacional. La Federación denunciaba que "el motivo de la oportunidad elegida por el Gobierno para invalidar las elecciones sale a la vista con la actitud de las empresas de abrir inmediatamente sus puertas bajo leoninas condiciones de trabajo para su personal".$^{33}$ La vinculación entre ambas decisiones estaba clara. En respuesta a esta resolución, asambleas realizadas en distintos puntos del país, incluido Rosario, ratificaron a las autoridades de la Comisión Nacional de Salarios, dispusieron no convocar a elecciones y dar continuidad al plan de lucha.

En Rosario, una asamblea general extraordinaria que contó con la participación de más de 2000 afiliados "resolvió por unanimidad no retornar al trabajo rechazando los puntos contenidos en el convenio laboral [patronal] por entender que el mismo [anulaba] por completo el сст/46 que regía para esta actividad". Con las puertas abiertas del frigorífico Swift y la ratificación del plan de lucha por parte del gremio, la prensa rosarina reflejaba los índices de acatamiento a la medida de fuerza. Durante semanas se daba cuenta de una escasa asistencia obrera que oscilaba en "unas 400 personas". Pasado un mes del fin del lock out la adhesión a la huelga continuaba siendo contundente, en Swift trabajaba "un reducido número de personas en su mayoría personal jerárquico" ${ }^{34}$ La situación era similar en otros puntos del país.

Los miembros de la Comisión de Salarios de la Federación buscaban ampliar la solidaridad y abrir canales de diálogo, los cuales continuaban siendo rechazados categóricamente por los sectores patronales. Ante la circulación de rumores sobre acercamientos entre las partes, los representantes

31 “Comunicado de prensa”, La Capital, Rosario, 19 y 20 de septiembre de 1962. FH-HBA, Rosario.

32 Decreto núm. 9524, 11 de septiembre de 1962. Daba lugar a la impugnación presentada por la Lista Blanca. Los frigoríficos conducidos por esta lista no se habían plegado a la huelga. La Federación acusaba a Escalada de negociar un convenio colectivo que incorporaba las cláusulas de productividad exigidas por las patronales. Informes laborales DIL. Septiembre de 1962. Núm. 31. BCEIL/CONICET, Buenos Aires.

${ }^{33}$ Informes laborales DiL. Septiembre de 1962. Núm. 31, p. 8. BCEIL/CONICET, Buenos Aires.

${ }^{34}$ La Capital, Rosario, 19 y 20 de septiembre de 1962. FH-HBA, Rosario. 
empresariales rápidamente desmentían los trascendidos y ratificaban que su accionar era "definitivamente irreversible y cualquier versión en contrario que tienda a hacer creer sobre una solución distinta es totalmente inexacta" ${ }^{35}$ El diálogo con los sectores del gobierno nacional también estaba bloqueado, así parece atestiguarlo las denuncias sindicales contra el мтуss por negarse a recibirlos en audiencias y frustrados intentos de mediación por parte del presidente de la nación. ${ }^{36}$ En este marco de creciente debilidad, unos 15000 trabajadores ocupados en frigoríficos pequeños y medianos de todo el país realizaron medidas de fuerza en solidaridad. ${ }^{37}$

Sin embargo, el rotundo fracaso de la estrategia dialoguista llevada adelante por la Federación fue conduciendo al levantamiento de la huelga. ${ }^{38}$ Hacia finales de octubre y durante el mes de noviembre de 1962 las seccionales sindicales de todo el país fueron definiendo la vuelta al trabajo.

En ese marco, en Rosario se incrementó el accionar de las fuerzas represivas. Fuentes sindicales denunciaban la actitud de hostigamiento permanente de la policía y guardia de caballería, impidiendo "a los trabajadores del gremio estar presentes en los accesos del local sindical" y reprimiendo a los que se acercaban a "leer los comunicados publicados en las pizarras, creando un clima de provocación y de violencia”. Se registraron también detenciones de mujeres manifestantes que intentaban impedir el ingreso de crumiros o "rompe" huelgas. ${ }^{39}$

Por su parte, los sectores gremiales ligados a la lista violeta de Jacinto Serbali fueron reforzando su accionar fraccional, y reunidos en asamblea convocada por fuera del espacio sindical definieron levantar la medida de fuerza. Ellos se arrogaban representatividad gremial esgrimiendo el argumento de que la Comisión Directiva, en funciones, no había sido reconocida por Swift. ${ }^{40}$

El 5 de noviembre la represión recrudeció al ser detenida parte de la Comisión Directiva sindical por arrojar "panfletos de neta orientación co-

35 "Comunicado de prensa", La Capital, Rosario, 20 de octubre de 1962. FH-HBA, Rosario.

${ }^{36}$ Informes laborales DIL. Octubre de 1962. Núm. 32. BCEIL/ConicEt, Buenos Aires.

${ }^{37}$ La Capital, Rosario, 18 de octubre de 1962. FH-HBA, Rosario.

${ }^{38}$ La Federación comunicaba a las filiares que "las empresas no aceptan ningún arreglo por cuanto para ellas el problema está resuelto y que, de acuerdo con esto, la Comisión de Salarios entendía que esto era un asunto liquidado". Libro de Actas 1960-1965 del Sindicato de Obreros y Empleados del Frigorífico "Cuatreros", citado en Baier (2012, p. 31).

${ }^{39}$ La Capital y La Tribuna, Rosario, 3 de octubre de 1962. FH-HBA, Rosario.

${ }^{40}$ La Tribuna, Rosario, 29 de octubre de 1962. FH-HBA, Rosario. La prensa rosarina informaba sobre reuniones y asambleas convocadas por la fracción gremial. 
munista" en las instalaciones de Swift. También se sucedieron despidos selectivos en Swift. El 8 de diciembre el Sindicato fue ocupado por la fracción gremial liderada por Serbali, en cumplimiento de una resolución emitida por el MTyss. ${ }^{41}$

En otros puntos del país el escenario del conflicto también se traducía en el recrudecimiento de internas sindicales. En Berisso, los trabajadores resolvieron retornar a la fábrica, bajo protestas, hacia finales del mes de noviembre en un clima de marcada hostilidad entre la organización sindical local y la Federación (Lobato, 2001). En CAP-Cuatreros de General Cerri, levantada la huelga, la desarticulación de la Comisión Directiva devino del accionar patronal a través de despidos de activistas, delegados y miembros directivos, incluido su secretario general (Baier, 2012).

En suma, la vuelta a las fábricas tras la derrota de la huelga estuvo atravesada, en un primer momento, por una clara arremetida patronal que se valió de los dispositivos del Estado para establecer un escenario signado por la pérdida de derechos laborales e intentos sistemáticos por atomizar y desarticular el colectivo de obreros. Tanto en Rosario como en otros puntos del país a las fuerzas represivas se les sumó la actuación de los funcionarios ministeriales que en sus intervenciones buscaron profundizar las tensiones sindicales. Finalizado el conflicto se produjo un claro desplazamiento de las conducciones sindicales que habían liderado la Huelga de los 100 días.

Con las organizaciones sindicales diezmadas, los esfuerzos patronales por debilitar la solidaridad obrera se ubicaron con fuerza en los lugares de trabajo. En efecto, una vez levantada la huelga, se multiplicaron los despidos de delegados y activistas. Además, la entrada del personal a las fábricas se realizaba al ritmo de las "necesidades" de las empresas. Entre aquellos que estaban en condiciones de ser convocados, el ingreso de cada obrero estaba atado a una aceptación personal de las transformaciones en la organización del trabajo que los sujetaba a condiciones de mayor explotación.

Ahora bien, ¿cuáles fueron los aspectos del proceso de trabajo que las patronales de la "industria grande" buscaban modificar y tras la derrota de la huelga, en gran medida, impusieron?

${ }^{41}$ La Capital, Rosario, 5 de noviembre y 8 de diciembre de 1962. FH-HBA. Rosario. 


\section{TRANSFORMACIONES EN LAS FORMAS DE ORGANIZAR EL TRABAJO. EL EPICENTRO DEL CONFLICTO}

Los representantes de los grandes frigoríficos postulaban la necesidad de incrementar la productividad del trabajo a través de nuevas formas de organizar la producción que desconocían derechos laborales conquistados. En su defensa apelaban a la crisis de los grandes frigoríficos. Como hicimos referencia en la introducción, el sector se encontraba atravesando una profunda reconfiguración a escala mundial con cambios en las pautas de exportación, consumo y producción de carnes. En Argentina y otros países de América del Sur comenzaron a instalarse frigoríficos más chicos y de capitales nacionales, mientras que la "industria grande" ingresó en una etapa de declive y retirada.

Desde la óptica empresarial esta crisis obedecía a dos razones: 1) "el alto costo de la mano de obra, motivado principalmente por la existencia de trabas y desviaciones" que afectaban a la producción, y 2) "la imposibilidad de lograr [...] el reequipamiento necesario". En tal sentido, afirmaban que era "imprescindible e inevitable establecer un ordenamiento de los trabajos" y repetían: "lo que concretamente se pretende es corregir trabas, vicios, deformaciones y abusos". ${ }^{2}$

La supuesta imposibilidad de obtener el reequipamiento necesario para incrementar la productividad del trabajo puede vincularse con una de las características más relevantes de la rama. En efecto, la frigorífica se caracteriza por ser, aún hoy, una industria que realiza una utilización intensiva de la fuerza de trabajo, con procesos productivos de tipo manual que demandan tareas de gran esfuerzo físico. En secciones claves se evidencia la existencia de trabajadores y trabajadoras que, valiéndose de herramientas sencillas, operan de forma directa sobre el objeto de trabajo. Esto implicaba que la intensificación recayera casi exclusivamente en un aumento de la explotación en intensidad, a través del incremento de los ritmos productivos, y en extensión, alargando la jornada laboral. Es importante tener en cuenta estas premisas a la hora de analizar los cambios que se irían introduciendo en los lugares de trabajo tras la "Huelga de los 100 días".

Al triangular información proveniente del ámbito sindical, de agrupaciones gremiales, partidarias y de la prensa nacional y local, es posible es-

42 Solicitada, La Capital, Rosario, 6 de septiembre de 1962. FH-HBA. Rosario. 
tablecer al menos tres núcleos generales que constituían el epicentro de las transformaciones: uno tenía que ver con el incremento en la velocidad del proceso productivo, otro con habilitar la movilidad de los trabajadores por distintos puestos y secciones y el tercero con limitar el accionar de la representación obrera dentro de la fábrica. Los tres aspectos mencionados tenían como denominador común establecer el dominio y la potestad unilateral de las empresas de disponer de su fuerza de trabajo.

Estos elementos se encontraban disgregados en una serie de puntos y las patronales daban cuenta de ellos deteniéndose en algunos aspectos; a modo de ejemplo, hacían referencia al régimen horario de los trabajadores que realizaban tareas insalubres y denunciaban que cobraban salarios por jornada completa, aunque realizaran menos horas de trabajo efectivo. Arremetían también contra el sistema de relevos ya que les resultaba "inadmisible que en algunos sectores para cada operación que ocupa un trabajador haya que mantener otro operario de relevo, esto afecta los costos y es un mal ejemplo para otros sectores que seguramente no comparten estos vicios y malas prácticas". Además se oponían a la forma en que se realizaba el pago al personal destajista, donde se reconocía la tarea con mayor retribución, y reivindicaban con especial énfasis la necesidad de establecer "préstamos y transferencias" de trabajadores entre distintos sectores. ${ }^{43}$

La disputa por disponer de la movilidad de los obreros dentro de la fábrica era un aspecto crucial en el marco de las transformaciones y se vinculaba con la detallada calificación de tareas incorporadas al CCT $/ 46 .{ }^{44}$ Como refiere Daniel James (1981), con la firma de ese convenio y en las sucesivas reglamentaciones suscritas, las escalas salariales se establecían de acuerdo con las calificaciones y descripción de tareas y se articulaban con cláusulas que garantizaban el mayor salario en caso de cambio de tareas. En documentos de la época se hacía referencia a que con la firma del сст/46 los trabajadores

${ }^{43}$ Informes laborales Dil. Septiembre de 1962. Núm. 31. BCEIL/Conicet. Buenos Aires. Solicitada, La Capital, Rosario, 6 de septiembre de 1962. FH-HBA. Rosario.

${ }^{44}$ Además del establecimiento de categorías, con el сст/46 se afirmaron una serie de normas significativas como la Garantía Horaria (que establecía el pago de 60 horas por quincenas cuando las empresas no pudieran suministrar trabajo), la jornada laboral para los trabajos insalubres en cámaras frías y la conformación de Comisiones Paritarias. Algunos de estos derechos reafirmaban conquistas que habían sido obtenidas tiempo atrás (Peter, 1968, pp. 179-181 y 198, 199). Periódico Defensor Gremial de la industria de la carne, Rosario, abril de 1946 . Fondo Documental Mikielievich. Rollos 003-M y 005-M. Archivo del Museo Histórico Provincial de Rosario “Dr. Julio Marc" (en adelante AMHPR), Rosario, Argentina. 
lograron limitar "la cantidad de traslados, respetando antigüedad y sin menoscabar las retribuciones". ${ }^{45}$ De manera que, las calificaciones y la detallada descripción de tareas fueron limitantes importantes para la movilidad obrera dentro de las fábricas y constituían herramientas legales que permitían poner un freno a la introducción de nuevas pautas de producción y a la multiplicación de suspensiones y despidos.

Con estas disposiciones generales, la importancia del сст/46 estuvo determinada por una correlación de fuerzas que, a lo largo del tiempo, permitió a los trabajadores disputar mejoras en las condiciones de trabajo y consolidar derechos laborales al interior de los lugares de trabajo a través de reglamentaciones internas y laudos arbitrales. Es por eso que en el marco del conflicto desatado en 1962 su defensa se erigió como una de las principales banderas del sector gremial.

Derrotada la "Huelga de los 100 días", el desconocimiento del сст/46 supuso un notorio empeoramiento de las condiciones de trabajo. Durante los meses de noviembre y diciembre de 1962 la vuelta a las fábricas fue extremadamente dura para sus trabajadores. Como mencionamos, la modalidad de ingreso individualizada y al ritmo de las "necesidades" productivas de las empresas implicó en los hechos numerosos despidos. En los principales frigoríficos del país las firmas violaban "impunemente" la legislación vigente en materia de "asociaciones profesionales de trabajo, convenios colectivos de trabajo e indemnizaciones por despido [...] imponiendo nuevas e inhumanas condiciones de trabajo". ${ }^{46}$

En Rosario, protagonistas de las jornadas de lucha recordaban que "centenares de obreros, después de tres meses de conflicto, quedaron en la calle. La empresa cesanteó a los más combativos. Quedó afuera toda la Comisión Directiva e impusieron condiciones de super explotación que hacía tiempo que no se veían, no se conocían. ${ }^{" 47}$ Otros testimonios hacen referencia a la firma de aceptación del "famoso papel de los veinte puntos. Eran todas las conquistas perdidas: el cuchillo será a cargo del obrero, las botas, esto, lo otro.

${ }^{45}$ Laborismo, Buenos Aires, 21 de junio de 1947, p. 2. s/ref. Agradezco a Gustavo Contreras el haberme facilitado el material.

${ }^{46}$ Informes laborales Dil. Abril de 1963. Núm. 38, p. 6. BCEIL/Conicet, Buenos Aires.

${ }^{47}$ Memorias escritas del militante comunista y obrero de Swift Santiago Simón, "Memorias de Santiago Simón, un trabajador del Frigorífico Swift”, s/ref., p. 9. 
Quitaban cincuenta años de conquistas de un plumazo. Y había que firmar eso para volver a entrar a laborar." 48

Distintos volantes que circulaban en las fábricas daban cuenta de los atropellos permanentes y generalizados, donde los más afectados eran los trabajadores que presentaban resistencias a adaptarse a las nuevas pautas productivas. Los boletines de fábrica describían las condiciones imperantes en distintas secciones de las plantas. En el frigorífico Armour de Berisso se denunciaban reducciones de sueldo, extensión horaria y "cambios arbitrarios e inconsultos de turnos" a trabajadoras de la sección Conserva, "particularmente a una compañera que tiene tres hijos uno de ellos de 45 días". ${ }^{49}$ También acusaban a la empresa de enviar obreros enfermos a las cámaras frías; de no pagar horas extras en secciones como Playa de novillo y de suprimir relevos en Playa de capones. En el Swift, por su parte, se registraron suspensiones "por errores cometidos en el proceso productivo" o por llegar tarde, $y$ despidos por "demoras en la realización de tareas" en la sección Curtiembre. ${ }^{50}$ En definitiva, las nuevas formas de organizar y gestionar la fuerza de trabajo facilitaron la multiplicación de despidos, cesantías y traslados de personal y redundaron en una forma de organizar el trabajo que avanzaba sobre derechos adquiridos.

\section{RECONSTRUCCIÓN GREMIAL Y DISPUTAS EN LA COTIDIANIDAD LABORAL. EL CONFLICTO CONTINÚA}

El escenario de acelerado deterioro de las condiciones de trabajo en las plantas frigoríficas se inscribió en un contexto de extremo debilitamiento de las conducciones sindicales tanto locales como nacionales que, como mencionamos, obedecía a diversos factores. La derrota de la huelga implicó el despido de "casi todos los cuerpos de delegados y comisiones directivas de los distin-

${ }^{48}$ Entrevista al militante del Partido Revolucionario de los Trabajadores (PRT), Luis Ortolani, realizada por Laura Pasquali, marzo-julio de 2007. En Pasquali (2011, p. 27).

${ }^{49}$ Boletín de fábrica El Activista de la Carne, Berisso, noviembre de 1963, núm. 1, p. 7. Documentos Primer Periodo. Fundación Pluma (en adelante FP), Berisso. Recuperado de: http:// fundacionpluma.info:8080/xmlui/handle/123456789/1

${ }^{50}$ Boletín de fábrica El Activista de la Carne, Berisso, noviembre de 1963, núm. 1. Documentos Primer Periodo. FP. Berisso. Recuperado de: http://fundacionpluma.info:8080/xmlui/ handle/123456789/1 
tos sindicatos". En Rosario, a los numerosos despidos se les sumaron detenciones a dirigentes y activistas vinculados con el PC acusados de "actitudes subversivas". ${ }^{51}$

Por su parte, la Federación continuaba inmersa en las disputas internas por la conducción nacional que implicaron durante el año 1963 intervenciones judiciales y ministeriales tendentes a convocar a nuevas elecciones. Las mismas finalmente se sustanciaron en noviembre de ese año asumiendo el cargo de secretario general Manuel Reche, vinculado al dirigente saliente Eleuterio Cardoso. ${ }^{52}$

Una vez normalizada en términos institucionales la vida gremial, la conducción entrante continuó desarrollando una estrategia dialoguista, centrando su accionar en reestablecer las relaciones con las patronales "de la industria grande" a través del pedido formal al MTyss de "iniciar las negociaciones tendientes a la concertación de una nueva convención que regule el régimen de remuneraciones" para el personal de la industria frigorífica. ${ }^{53}$ El pedido iba acompañado de un anteproyecto donde se establecían "bases mínimas" que debían "presidir las nuevas tratativas" a través de cinco puntos entre los que se destacaban: la reimplantación de las condiciones laborales establecidas por el сст/46 "que fuera ilegal y unilateralmente derogado por las empresas"; incremento de salario en un 100\%; otorgamientos de beneficios adicionales (por cargas familiares, licencias, permisos y días no laborables) y aportes patronales con destino a la Federación..$^{54}$

Durante tres meses, las discusiones paritarias giraron en torno a la legitimidad/ilegitimidad del accionar de las empresas en cuanto a la derogación del сст/46 y el establecimiento de nuevas modalidades productivas. Las empresas defendieron su proceder "con arreglo a derecho y en uso de facultades propias", como prueba apelaban a la aceptación de las condiciones de trabajo actuales por parte de "cada obrero y empleado en servicio". Subrayaron desde

51 Informes laborales DIL. Abril de 1963. Núm. 38, p. 7. BCEIL/Conicet, Buenos Aires.

${ }_{52}$ Informes laborales DIL. Agosto, octubre y noviembre de 1963. Núm. 42, 44, 45. BCEIL/ Conicet. Buenos Aires.

${ }^{53}$ Expediente del мтуss tratativas para renovar convenio colectivo para los trabajadores de la industria frigorífica (industria grande). Buenos Aires, 20 de diciembre de 1963. Exp. 387006/64, f. 1. Fondo Archivo Intermedio. Archivo General de la Nación del mтyss (en adelante AGN), Buenos Aires.

54 Expediente del MTyss tratativas para renovar convenio colectivo para los trabajadores de la industria frigorífica (industria grande). Buenos Aires, enero de 1964. Exp. 387006/64, f. 3. Fondo Archivo Intermedio. AGN, Buenos Aires. 
el primer día que cualquier aumento salarial implicaba inexorablemente "la aceptación de las condiciones actuales de trabajo". Por su parte la Federación insistía en el carácter ilegal y arbitrario de dichas condiciones laborales y denunciaba que resultaba "inaceptable pretender que por el hecho de que los trabajadores se estén desempeñando en esas condiciones signifique haber aceptado las mismas [...] los trabajadores fueron obligados a trabajar en dichas condiciones, por imposición de una necesidad ineludible" ${ }^{55}$ Aunque había acuerdo en la necesidad de establecer un nuevo Convenio Colectivo, la discusión se centraba en las bases para su elaboración. Mientras que la parte gremial defendía la vigencia del сст/46, la patronal buscaba la aceptación formal por parte de la Federación de las nuevas condiciones laborales.

En el transcurso de las negociaciones, la Federación solicitó un aumento salarial anticipado que fue rápidamente rechazado por los empresarios quienes en todo momento se mantuvieron reacios a declinar los puntos esenciales de su propuesta: otorgar legalidad a las condiciones laborales que se estaban implementando de hecho en las plantas industriales mediante la firma de un nuevo сст. Finalmente, la parte sindical cedió ante las exigencias patronales aduciendo que lo hacía "exclusivamente, porque no puede omitir la angustiosa urgencia con que debe llegar a los trabajadores un aumento que alivie la situación que padecen" ${ }^{56} \mathrm{El}$ aumento salarial obtenido fue de $33 \%,{ }^{57}$ muy por debajo de las aspiraciones sindicales iniciales.

Con la firma del сст 41/64 adquirieron fuerza de ley aspectos nodales de las transformaciones en curso. Los temas centrales eran: 1 . Sistema de Incentivación o premios. Los mismos podían "ser instituidos o suprimidos por las empresas" (art. 3); 2. Jornada de Trabajo. Las empresas podían fijar o modificar horarios que debían ser "respetados por obreros y empleados". El tiempo destinado al almuerzo o descanso dejaba de ser abonado y quedaban prohibidas las ausencias o descansos por fuera del horario estipulado para tal fin, asimismo el abandono del puesto de trabajo sólo podrá hacerse con autorización del supervisor (art. 10); 3. Prestamos y transferencias. Las empresas

55 Expediente del Mтуss tratativas para renovar convenio colectivo para los trabajadores de la industria frigorífica (industria grande). Buenos Aires, enero de 1964. Exp. 387006/64, f. 19. Fondo Archivo Intermedio. AGN, Buenos Aires.

56 Expediente del MTyss tratativas para renovar convenio colectivo para los trabajadores de la industria frigorífica (industria grande). Buenos Aires, 27 de febrero de 1964. Exp. 387006/64, f. 35. Fondo Archivo Intermedio. AGN, Buenos Aires.

57 Informes laborales DIL. Marzo de 1964. Núm. 49. BCEIL/CONICET, Buenos Aires. 
podían disponer de personal para cubrir cualquier "lugar o tarea" sin previo $\operatorname{aviso}^{58}$ (art. 11) y 4. Eficiencia y calidad de la producción. Se estableció que las empresas tenían "derecho a recabar de sus trabajadores, en todas las etapas del proceso productivo, la calidad requerida; fijar la operación del hombre hora en cada operación [...]; fijar la velocidad en que deben operar las maquinarias y equipos" ${ }^{\prime 59}$ (art. 12). Otras disposiciones habilitaban a las patronales efectuar despidos a trabajadores con cinco años de antigüedad (art. 17) y establecían que el "personal transitorio y eventual quedaba sujetos a la aplicación de convenios y usos locales" (art. 23). También se firmaron artículos tendentes a limitar la presencia gremial en los lugares de trabajo reduciendo a uno el número de delegados "por cada ciento cincuenta trabajadores" (art. 19) y a disminuir el poder de dichos representantes al establecer que "los reclamos que creyere necesario efectuar el personal comprendido en este Convenio, deberá ser formulado en primer término, ante el superior inmediato", recién en un segundo momento, y siempre que no se hubiera arribado a una solución satisfactoria, los trabajadores podrían recurrir a su delegado (art. 18). ${ }^{60}$

El Convenio estaba muy lejos de dar respuestas a las problemáticas más urgentes de los trabajadores, por el contrario reafirmaba "inhumanas" condiciones de trabajo las cuales tomaban peso de ley, mantenía vigente el atraso salarial y daba lugar a la profusión de suspensiones y despidos en distintas firmas del sector. ${ }^{61}$ Con este desenlace se cerraba una etapa de luchas significativas del gremio de la carne con un resultado favorable a las patronales quienes consiguieron morigerar los efectos de la crisis de la industria imponiendo un profundo deterioro en las condiciones de trabajo.

${ }^{58}$ Estaban exceptuados los empleados de cámaras frías que debían tener un día de previo aviso para ser transferidos o prestados a otras secciones. Pero se dejaba expresamente fijado que, si mediaba consentimiento del interesado, el traslado podía ser el mismo día. Convenio Colectivo Industria Grande de la Carne. 3 de marzo de 1964. Exp. 387006/CCT 41/64, f. 41, hoja 5, p. 5. Fondo Archivo Intermedio. AGN, Buenos Aires.

${ }_{59}$ Convenio Colectivo Industria Grande de la Carne. 3 de marzo de 1964. Exp. 387006/ CCT 41/64, f. 56, hoja 8, p. 8. Fondo Archivo Intermedio. AGN, Buenos Aires.

${ }^{60}$ Convenio Colectivo Industria Grande de la Carne. 3 de marzo 1964. Exp. 387006/CCT 41/64, f. 58, f. 59, f. 60, hojas 10, 11 y 12, pp. 10, 11 y 12. Fondo Archivo Intermedio. AGN, Buenos Aires.

${ }^{61}$ Aun mientras se estaban llevando adelante las negociaciones las empresas no dejaban de suspender y despedir trabajadores. La Federación denunciaba 680 suspensiones en el frigorífico Anglo; 180 en Swift de Rosario; 1200 en el Armour y Swift de Berisso, y 2000 despidos en los frigoríficos de Entre Ríos. Informes laborales DIL. Febrero y marzo de 1964. Núms. 48 y 51. BCEIL/CONICET, Buenos Aires. 
Algunos autores interpretaron que con el fin de la huelga y la firma de un nuevo convenio que eliminaba importantes conquistas obreras se cerró definitivamente una época de esplendor. Esta situación expresaba la crisis del sector industrial y "el alto grado de compromiso de la burocracia sindical" con las patronales (Schneider, 2005). Otros han analizado el conflicto de los trabajadores de los frigoríficos y la firma del сст/64 en el marco de los procesos de racionalización de la producción que culminaron con un cambio en el balance de fuerzas en los lugares de trabajo a favor de las patronales, principalmente por el debilitamiento de la presencia de delegados en planta y comisiones internas. En tal sentido, estos procesos expresarían la desmovilización de la clase obrera producto de la avanzada patronal y habrían contribuido al refuerzo de la burocracia sindical (James, 1981).

Lo cierto es que la arremetida patronal parecía no tener límites y en esa carrera la dirigencia sindical no salía favorecida. Por el contrario, la opción por el diálogo y la búsqueda incesante de los dirigentes de la Federación por reubicarse como interlocutores válidos ante una patronal efervorizada tenía su contrapartida en las vivencias cotidianas de miles de obreros de los frigoríficos. Es precisamente al calor de esa cotidianidad signada por la dureza de las condiciones de trabajo que comenzó a surgir un nuevo activismo en las fábricas articulando el accionar de trabajadores combativos con militantes provenientes de partidos de la izquierda.

En Rosario, luego de producida la intervención del sindicato, la lista Marrón, aunque claramente debilitada, mantuvo su presencia en el gremio de la carne durante décadas. Asimismo, tras la derrota de la "Huelga de los 100 días" se identifica el nacimiento de una corriente clasista con importante actuación en los principales frigoríficos del país, principalmente en Rosario y Berisso. Así, durante los años 1963, 1964 y 1965 comenzó a crecer el autodenominado Movimiento Renovador, luego El Activista de la Carne, ${ }^{62}$ dirigido por el partido trotskista Palabra Obrera. Una serie de dimensiones caracterizan a esta experiencia de organización gremial, en primer lugar, el impacto de la huelga y la crítica profunda a los dirigentes sindicales de los sectores cardosistas y de aquellos vinculados con Escalada denunciados por traición y por "carneros", respectivamente. En segundo lugar, la identificación y el acercamiento a los trabajadores activistas dispuestos a resistir el embate patronal.

${ }^{62}$ Boletín de fábrica Movimiento Renovador de la Carne, Berisso, 24 de marzo de 1963. Documentos Primer Periodo. FP. Recuperado de http:// http:/fundacionpluma.info:8080/xmlui/ 
En tercer lugar, el desarrollo de una estrategia de reorganización focalizada en los lugares de trabajo promoviendo elecciones de delegados y la conformación de Comisiones Internas de Fábrica. Durante esos años se identifica la presencia de militantes de izquierda con trabajo político al interior de las plantas o con una presencia periférica a través de pintadas o yendo a "las puertas de las fábricas a las cinco y media de la mañana con volantes". ${ }^{63}$

En la configuración de esta experiencia gremial la firma del CCT 41/64 fue significativa ya que, más allá de las críticas, orientó el trabajo del Movimiento Renovador hacia el cumplimiento de aquellas "conquistas que la Patronal" no habían "podido tocar" por tratarse de disposiciones vinculadas con leyes y decretos que excedían la instancia paritaria. En efecto, el СCT 41/64 no eliminó artículos importantes como la Garantía Horaria; el pago mayor en el caso de transferencias de obreros a secciones o tareas de menor remuneración y el respeto a la antigüedad en el caso de despidos. Sin embargo, estas disposiciones legales no eran cumplidas en los lugares de trabajo "donde el impacto de la derrota" era "tan profundo que ni siquiera se puede garantizar el piso de derechos que el convenio reconoce". ${ }^{64}$

Para la organización de izquierda, la tarea gremial era, entonces, elegir representantes por secciones para hacer cumplir derechos y disputar nuevas conquistas, "depende de los delegados diferenciar cuál es el problema más sentido por la sección y dar la batalla por conseguir poco a poco nuestros objetivos [...] que sea la sección la que decida ante cada problema cuál es el camino a seguir". ${ }^{65}$

La reconstrucción gremial implicaba asimismo el acercamiento a las listas y referentes opositores a las corrientes cardosistas. En Rosario, el surgimiento de esta experiencia gremial combativa tuvo, en sus orígenes, un perfil más periférico y articulado a las listas y agrupaciones que iban emergiendo en el cotidiano fabril. Como hicimos referencia, la derrota de la huelga se traducía a nivel local en la intervención sindical y la persecución a los dirigentes rosarinos ligados al Partido Comunista, esto implicó que "en Swift, virtual-

${ }^{63}$ Entrevista al militante del Partido Revolucionario de los Trabajadores (PRT), Luis Ortolani, realizada por Laura Pasquali, marzo-julio de 2007. En Pasquali (2011, p. 25).

64 "Carne. Otra "Cardoseada", Palabra Obrera, Buenos Aires, 21 de abril de 1964, año vi, núm. 360, p. 10. Hemeroteca. Centro de Documentación e Investigación de la Cultura de Izquierdas (en adelante CedincI), Buenos Aires.

${ }^{65}$ Boletín de fábrica El Activista de la Carne, Berisso, 21 de marzo de 1964, núm. 2, p. 8. Documentos Primer Periodo. Fr. Recuperado de http://fundacionpluma.info:8080/xmlui/ 
mente, había que empezar de nuevo. Había que recomponer, reiniciar, una tarea que tenía a favor una tradición reciente" (Shapiro, 2015, p. 138).

En este contexto, el nuevo activismo gremial brindó su apoyo a la Lista Blanca y Negra, liderada por Gerardo Cabrera, que luego de perder las elecciones locales de 1963 articuló su accionar en la construcción del cuerpo de delegados de Swift. Palabra Obrera caracterizaba a esta lista como "una corriente de clase aunque con grandes desviaciones sindicaleras [sic]", y valoraban "el hecho de que estén muy en contacto con nosotros puede hacer que Rosario pase al frente del gremio". ${ }^{66}$ Estas predicciones no se cumplieron. Aunque la lista Blanca y Negra fue consolidando su liderazgo, los iniciales vínculos con corrientes de izquierda pronto se disolvieron y, cuando finalmente asumió la conducción del sindicato local en 1969, se encontraba asociada a sectores de la derecha peronista. ${ }^{67}$ De manera que el fortalecimiento de organizaciones clasistas en los frigoríficos de Rosario se vio acompañada de procesos de proletarización de militantes de partidos de izquierda como el Partido Revolucionario de los Trabajadores (Torres y Scoppetta, 2015; Vogelmann, 2013).

Aunque es preciso no exagerar la efectiva presencia y fortaleza de las organizaciones gremiales de izquierda combativa en las plantas frigoríficas durante el periodo, sí interesa destacar la incidencia que este nuevo activismo fue cobrando en años posteriores al interior del gremio, particularmente en momentos de creciente radicalización de las luchas obreras hacia finales de la década de los sesenta. En Rosario tuvieron actuación la agrupación La Chaira de los trabajadores de la carne que reunía a militantes y activistas de distintos partidos de izquierd ${ }^{68}$ y a trabajadores sin adscripción partidaria. A comienzos de la década de los setenta surgió otro agrupamiento de izquierda en los frigoríficos rosarinos nucleados alrededor de Lista Rosada. Experiencias gremiales combativas, con un claro anclaje en los lugares de trabajo y articuladas a la actuación de delegados y activistas por secciones mantuvieron su vitalidad durante las décadas de los ochenta y noventa en los frigoríficos

${ }^{66}$ Boletín de fábrica El Militante, 8 de mayo de 1964, núm. 16, p. 6. Documentos Primer Periodo. FP. Recuperado de http://fundacionpluma.info:8080/xmlui/

${ }^{67}$ La Lista Blanca y Negra dirigió el sindicato de la carne de Rosario desde 1969 primero como intervención y luego a través de elecciones. Lideró el gremio por casi tres décadas, sus principales referentes fueron figuras políticas del peronismo santafesino quienes llegaron a ocupar cargos legislativos (Vogelmann, 2012).

${ }^{68}$ Partido Comunista Revolucionario; Socialismo Revolucionario; Partido Revolucionario de los Trabajadores, Vanguardia Comunista; Partido Socialista de los Trabajadores, entre otros. 
de la región. La organización en los lugares de trabajo, los reclamos que visibilizaban las problemáticas laborales cotidianas y la construcción de listas y agrupaciones opositoras a las condiciones sindicales van a ser sellos distintivos de esas corrientes.

\section{REFLEXIONES FINALES}

La "Huelga de los 100 días", protagonizada por los obreros de frigoríficos más importantes de Argentina, supuso un momento de inflexión en la dinámica gremial. Se originó por la exigencia empresarial de realizar modificaciones en la organización del trabajo, en el marco de reclamos sindicales por aumentos salariales. Con la derrota se instrumentaron transformaciones en los procesos productivos que implicaron pérdida de derechos laborales e intensificación del trabajo, los más importantes fueron el incremento en la velocidad de los procesos productivos, la movilidad de los trabajadores por distintos puestos y secciones, y la limitación del accionar sindical dentro de la fábrica. En ese contexto de importante deterioro de las condiciones laborales, identificamos cómo fue surgiendo un nuevo activismo gremial al interior de los espacios de trabajo. De manera que, el conflicto analizado, brinda indicios para reflexionar en torno a la potencialidad de los procesos de organización gremial que se consolidaron en los espacios laborales.

Hemos analizado cómo el conflicto sobrepasó la experiencia de la gran huelga, buscando iluminar las transformaciones que se fueron estableciendo en los procesos de trabajo y las tensiones y lucha al interior de las organizaciones sindicales y en la cotidianidad laboral en las fábricas. El enfoque buscó indagar en las relaciones que se establecieron entre la escala nacional y la región sur de Rosario, polo de desarrollo de la industria frigorífica en el país. En tal sentido, se han ponderado un conjunto de dimensiones imprescindibles al momento de reconstruir la complejidad del proceso y se identificó el accionar de los principales actores involucrados.

Fueron abordadas las políticas y el accionar de las patronales de la llamada "industria grande", con su negativa a negociar los aspectos centrales de su proyecto, o sea, incrementar la productividad del trabajo a través de nuevas formas de organización que desconocían derechos laborales. Durante el periodo bajo estudio, la conflictividad laboral originada por la imposición de cambios en los procesos de trabajo, tendentes a reestablecer el mando pa- 
tronal al interior de los espacios laborales, atravesó a distintos sectores, tanto industriales como de servicio. En la industria frigorífica dicha conflictividad estuvo vinculada estrechamente con la forma de utilización intensiva de la fuerza de trabajo que caracteriza al sector y con la profunda reestructuración por la que estaba atravesando la rama a nivel mundial que determinó un proceso de declive y retirada de los capitales concentrados. De manera que, aunque la respuesta patronal ante la declaración de medidas de fuerza contaba con antecedentes, el proceso bajo estudio se diferenció de otros conflictos por la extensión del lock out y por el indeclinable posicionamiento a clausurar todo espacio de diálogo y negociación durante la huelga. Es posible pensar que los grandes frigoríficos de capitales extranjeros estaban preparando sus retiradas del país procurando instalar formas de explotación del trabajo que emulaban a las de principios del siglo xx.

En Rosario, el frigorífico Swift venía desarrollando una política de clausura de ámbitos de diálogo y negociación con el sindicato local. En efecto, antes y durante el conflicto sostuvo una política de abierta hostilidad al desconocer a su comisión directiva liderada por el Partido Comunista.

Las fuerzas represivas del Estados fueron otro de los actores significativo en esta trama, custodiando las plantas industriales en el marco del lock out y reprimiendo intentos de ocupación obrera. En Rosario, su accionar se vio exacerbado por la persecución al comunismo reprimiendo manifestaciones $y$, sobre el final de la huelga, encarcelando a activistas y dirigentes sindicales comunistas acusados de "actitudes subversivas".

Un actor central en el conflicto fueron las organizaciones sindicales a nivel nacional y local. Además de las estrategias seguidas y las medidas de lucha adoptadas, identificamos tensiones y disputas que crecían al interior de las organizaciones obreras y el accionar del poder ejecutivo nacional instrumentando mecanismos tendentes a promover las diferencias. Las disputas fueron de distinto orden, en el plano nacional se desarrollaron por la conducción de la Federación, ya que no estaban en tensión programas ni estrategias antagónicas entre los sectores en pugna, en tanto compartían prácticas sindicales dialoguistas y negociadoras.

En el espacio regional sí se dirimían diferencias más profundas entre la conducción sindical dirigida por el PC y un sector del sindicalismo peronista. Durante el conflicto, la estrategia desarrollada por el sindicato rosarino estuvo dada en activar movilizaciones y sostener la unidad de los trabajadores a través de asambleas, organización de comisiones, actividades de difusión y 
establecer la sede sindical como espacio de encuentro y de información. Por su parte, a nivel nacional la Federación buscó profundizar su estrategia dialoguista tendente a constituir ámbitos de negociación con el sector patronal que fueron sistemáticamente denegados. Es posible afirmar el rotundo fracaso de dicha estrategia en el desarrollo del conflicto, no sólo durante el transcurso de la gran huelga sino con posterioridad, en el contexto de las negociaciones paritarias, cuando las patronales lograron otorgar carácter de ley a muchas de las nuevas modalidades productivas que se estaban implementado de hecho en los espacios laborales.

Por último, al dar cuenta de la cotidianidad del conflicto y el trabajo, analizamos el accionar de los obreros en el transcurso de la huelga, el impacto de la derrota a nivel de planta y la desarticulación de las conducciones sindicales. También nos detuvimos en el surgimiento de un nuevo activismo gremial en las fábricas que nació al calor del deterioro de las condiciones laborales y la crisis de las conducciones sindicales. En tal sentido, el escenario en las fábricas tras la derrota de la gran huelga y la firma del nuevo convenio colectivo más que de desmoralización y desmovilización estuvo signado por la aparición de experiencias de organización en los lugares de trabajo que lucharon por el cumplimiento de derechos laborales que las patronales no habían podido suprimir. En Rosario, se advierte la incidencia de este nuevo activismo gremial combativo y vinculado con sectores de izquierda que va a cobrar protagonismo en los procesos de radicalización de las luchas obreras de finales de la década de los sesenta y que mantuvieron su presencia durante años.

\section{LISTA DE REFERENCIAS}

Azcuy Ameghino, E. (2007). La carne vacuna argentina. Historia, actualidad y problemas de una agroindustria tradicional. Buenos Aires: ImagoMundi.

Baier, F. (2012). Lucha y resistencia obrera en la industria de la carne: la huelga nacional de 1962 en el frigorífico CAP-Cuatreros. (Tesis de licenciatura inédita), Universidad Nacional del Sur, Bahía Blanca. Recuperado de http://repositoriodigital.uns.edu.ar/ Balvé, B. y Balvé, B. (2005). El '69 huelgas políticas de masas. Buenos Aires: RyR.

Basualdo, V. (2010). Los delegados y las comisiones internas en la historia argentina: 1943-2007. En M. Schorr, V. Basualdo y D. Azpiazu, La industria y el sindicalismo de base en la Argentina (pp. 81-157). Buenos Aires: Atuel. 
Brennan, J. (1996). El Cordobazo. Las guerras obreras en Córdoba. 1955-1976. Buenos Aires: Sudamericana.

Bretal, E. (2016) La Edad de Oro en las representaciones de exobreros del frigorífico Swift de Berisso. Trabajo y Sociedad, 27, 291-304.

Buxedas, M. (1983). La industria frigorífica en el Río de la Plata (1959-1977). Buenos Aires: Clacso.

Campos J. y Campos L. (2017). El modelo argentino de representación de los trabajadores en los lugares de trabajo. RELATS-FORO RLT. Recuperado de http://www. relats.org/

Cerutti, L. y Resels, M. (2006). Democracia directa y gestión obrera. Rosario: Del Castillo.

De Oliveira, C. (2015). O fechamento da Swift na cidade do Rio Grande (1960): o pior revellion de todos os tempos. Ponencia presentada en Simpósio Nacional de História, Florianópoli, Brasil. Recuperado de http://www.snh2015.anpuh.org/

Doyon, L. (2006). Perón y los trabajadores. Los orígenes del sindicalismo peronista, 19431955. Buenos Aires: Siglo XXI.

Fayó, I. (2007). La institucionalización de la intervención de las Fuerzas Armadas argentinas en política interna. La ley 13234: inauguración de una nueva modalidad represiva, 1958-1961. Ponencia presentada en las XI Jornadas Interescuelas/Departamentos de Historia, Tucumán, Argentina.

Fernández, S. (2007). Los estudios de historia regional y local: de la base territorial a la perspectiva teórico-metodológica. En S. Fernández (comp.), Más allá del territorio: la historia regional y local como problema. Discusiones, balances y proyecciones. Rosario: Prohistoria Ediciones.

Ferraro, N. y Schiavi, M. (2012). La resistencia obrera en el largo plazo: racionalización industrial y luchas obreras en una coyuntura crítica (1954-1956). H-Industri@, 11, 37-59. Recuperado de http://ojs.econ.uba.ar/

Gayoso, N. y García Repetto, U. (2013). Protección frente al desempleo estacional y bolsas de trabajo en Uruguay (1944-1979). Montevideo: Universidad de la República (Serie Documentos de Trabajo).

Ghigliani, P. (2015). La conflictividad laboral en la industria gráfica (1966-1976). En A. Schneider y P. Ghigliani (comps.), Clase obrera, sindicatos y Estado: Argentina (19552010). Buenos Aires: ImagoMundi.

Gilly, A. (1986). La anomalía argentina. Cuadernos del Sur, 4, 5-39.

Gordillo, M. (1999). Córdoba en los '60. Córdoba: Imprenta de la Secretaría de Extensión Universitaria-Universidad Nacional de Córdoba.

Historia de la Federación de la Carne (1997). Buenos Aires: Publicación Sindical. 
James, D. (1981). Racionalización y respuesta de la clase obrera. Desarrollo Económico, 83, 321-349.

James, D. (2006). Resistencia e integración. El peronismo y la clase trabajadora argentina, 1946-1976. Buenos Aires: Siglo XIX.

Lobato, M. (2001). La vida en las fábricas. Trabajo, protesta y política en una comunidad obrera (1904-1970). Buenos Aires: Entrepasados.

Löbbe, H. (2009). La guerrilla fabril. Clase obrera e izquierda en las Coordinadoras de Zona Norte del Gran Buenos Aires (1975-1976). Buenos Aires: RyR.

Menotti, P. (2008). Al sur, un faro de luces y sombras. Historias de militancia, trabajo y explotación en el Swift. (Tesis de licenciatura inédita). Universidad Nacional de Rosario, Argentina.

Michelon, F. (2012). Sociedade Anônima Frigorífico Anglo de Pelotas: o trabalho do passado nas fotografias do presente. Pelotas: Editora e Gráfica Universitária. Recuperado de https://wp.ufpel.edu.br/

Pasquali, L. (2010). Éramos jóvenes pero también obreros. En L. Pasquali y O. Videla (eds.), El contenido de los conflictos. Formas de luchas sociopolíticas en la historia argentina reciente. 1966-1996 (pp. 25-42). Rosario: La Quinta Pata \& Camino Ediciones.

Pasquali, L. (2011). El PRT-ERP en Rosario. Entrevista con Luis Ortolani. Rosario: Edición del Autor.

Peter, J. (1968). Crónicas proletarias. Buenos Aires: Editorial Esfera.

Porrini, R. (2004). Memoria histórica e historias de bancarios y "friyeros". En R. Porrini (comp.), Historia y memoria del mundo del trabajo (pp. 65-87). Montevideo: Facultad de Humanidades y Ciencias de la Educación-Universidad de la República.

Porrini, R. (2018). Aproximación al estudio de un barrio de trabajadores: el Cerro (Montevideo) en los años cincuenta y sesenta. En S. Simonassi y D. Dicósimo (comps.), Trabajadores y sindicatos en Latinoamérica (pp. 153-176). Buenos Aires: ImagoMundi.

Salas, E. (2006). La resistencia peronista. La toma del frigorífico Lisandro de la Torre. Buenos Aires: Retórica.

Schneider, A. (2005). Compañeros. Trabajadores, izquierda y peronismo en la Argentina, 1950-1973, Buenos Aires: ImagoMundi.

Schvarzer, J. (1996). La industria que supimos conseguir. Una historia político-social de la industria argentina. Buenos Aires: Planeta.

Shapiro, J. (2015). Asalto a la democracia sindical. Rosario: Cuaderno.

Simonassi, S. (2016a). Procesos nacionales y dinámicas regionales: sectores productivos, conflictividad y organización en Rosario, Argentina, durante la década del sesenta. Ponencia 
presentada en el V Congreso Latinoamericano de Historia Económica, San Pablo, Brasil.

Simonassi, S. (2016b). Políticas patronales de disciplinamiento y conflictividad obrera en el Gran Rosario: continuidades y rupturas (1930-1980). Travesía, Suplemento, 182. VII Reunión del Comité Académico de Historia. AUgM. (pp. 381-405). Recuperado de http://www.travesia-unt.org.ar/

Simonassi, S. y Vogelmann, V. (2017). Aliados incómodos. Tradiciones obreras y sindicales en Rosario a principios de los años sesenta. Izquierdas, 34, 231-259. Recuperado de http://dx.doi.org/10.4067/S0718-50492017000300231

Simonassi, S. y Vogelmann, V. (2018). Pegar un chiflido y juntar gente. La conflictividad obrera en el Gran Rosario, 1955-1962. En S. Simonassi y D. Dicósimo (comps.), Trabajadores y sindicatos en Latinoamérica (pp. 153-176). Buenos Aires: ImagoMundi.

Torres, P. y Scoppetta, L. (2015). La apuesta armada: la parábola del PRT-ERP en el frigorífico Swift. (1965-1976). Ponencia presentada en las IV Jornadas Interdisciplinarias de Investigaciones Regionales, Mendoza, Argentina.

Viano, C. (2000). Una ciudad movilizada (1966-1976). En A. Pla (comp.), Rosario en la historia (t. 2, pp. 23-102). Rosario: UNR Editora.

Vogelmann, V. (2012). Trabajadores y reconversión en la industria frigorífica. Las experiencias gremiales de los trabajadores de la carne del Gran Rosario. (Tesis de doctorado inédita). Universidad Nacional de Rosario, Argentina.

Vogelmann, V. (2013). Los trabajadores de la carne del Gran Rosario. Organización gremial y conflictividad laboral 1969-1976. Historia Regional, 31, 115-138. Recuperado de http://historiaregional.org/ojs/index.php/historiaregional/article/ view/34/166

Vogelmann, V. (2015). Los trabajadores industriales en épocas de ajuste y flexibilización. Conflictividad y crisis en la industria frigorífica argentina durante la década de 1990. A Contracorriente, 12(3), 158-186. Recuperado de http://historiaregional. org/ojs/index.php/historiaregional/article/view/34

Vogelmann, V. y Menotti, P (2010). Los trabajadores de la carne de Rosario durante la primera mitad del siglo Xx. Ponencia presentada en las II Jornadas Internacionales de Problemas Latinoamericanos, Córdoba, Argentina. 


\section{OTRAS FUENTES}

Archivos

AGG-PC

Archivo Gastón Gesrik. Partido Comunista Provincia de Santa Fe, Rosario, Argentina.

AGN Archivo General de la Nación, Buenos Aires, Argentina.

AMHPR Archivo del Museo Histórico Provincial de Rosario "Dr. Julio Marc", Rosario, Argentina.

BCEIL/CONICET Biblioteca del Centro de Estudios e Investigaciones Laborales del Consejo Nacional de Investigaciones Científicas y Técnicas, Buenos Aires, Argentina.

CEDINC ICentro de Documentación e Investigación de la Cultura de Izquierdas, Buenos Aires, Argentina.

CD-TB Centro de documentación de las organizaciones político-militares argentinas-El Topo Blindado, en http://eltopoblindado.com

FH-HBA Fondo Hemerográfico. Biblioteca Argentina Dr. Juan Álvarez, Rosario, Argentina.

FP

Fundación Pluma, Argentina http://fundacionpluma.info:8080/ xmlui/handle/123456789/1

\section{Hemerografía}

Crónica.

Defensor Gremial.

El Activista de la Carne.

El Militante.

Laborismo.

La Capital.

La Prensa.

La Tribuna.

Nuestra Palabra. 